\title{
Clinical guidelines for treating von Willebrand disease patients who are not candidates for DDAVP - a survey of European physicians
}

\author{
J. M. LUSHER \\ Children's Hospital of Michigan and Wayne State University School of Medicine, Detroit, Michigan, USA
}

Summary. While certain plasma-derived factor VIII/ von Willebrand factor (FVIII/vWF) concentrates have proven to be quite useful in preventing or controlling bleeding in persons with von Willebrand disease who are not candidates for DDAVP, most of the information concerning dosage and effectiveness has been anecdotal. Additionally, the laboratory tests used to quantify vWF (the vWF:RCoF assay and collagen binding assay) are not well standardized. Thus, the US Food and Drug Administration (FDA) has been reluctant to grant licensed indication for use of these products in von Willebrand disease.

This brief report describes a survey of non-US physicians (from major centres) who are recognized experts in haemophilia and von Willebrand disease. Twenty-four of 27 questionnaires were completed, returned and analysed. Products thought to be effective in von Willebrand disease included Haemate $\mathrm{P}^{\circledR}$, Facteur von Willebrand ${ }^{\circledR}$, Alphanate ${ }^{\circledR}$, and the UK's BPL ' $8 \mathrm{Y}^{\text {, }}{ }^{\circledR}$. In calculating dosage to stop or prevent bleeding, most aim for a certain level of both FVIII and vWF:RCoF. Postoperatively, 16/24 re- spondents follow both of these laboratory tests once daily. Twenty-two of 24 would follow FVIII levels once daily. It is noteworthy that FVIII assay results are generally the only test results readily available to guide the respondents' clinical decisions.

For treatment of significant mucous membrane bleeding, respondents often individualize dosage and monitoring, depending on the type, location and extent of bleeding. Gastrointestinal bleeding is generally treated more aggressively. Patient monitoring varies between merely looking for cessation of bleeding, to a battery of laboratory tests, including haemoglobin and haematocrit. Seven out of 24 would monitor BT as well.

In addition to FVIII content, 22/24 respondents noted that they would find it helpful to have vWF:RCoF listed on the label, while 15/24 would like to know the vWF multimeric composition.

Keywords: von Willebrand disease, ristocetin cofactor assay, bleeding time, labelling of concentrates, mucous membrane bleeding, major surgery.
Although certain intermediate purity, virally attenuated FVIII concentrates have been used to treat patients with von Willebrand disease in the USA, Europe, and elsewhere over the past two decades [110], none of these concentrates has a licensed indication for use in von Willebrand disease. At least two pharmaceutical companies have recently requested such indication from the United States Food and Drug Administration (FDA). While it would seem that the extensive experience in von Willebrand disease patients with certain of these products should

Correspondence: Dr J. M. Lusher, Children's Hospital of Michigan, 3901 Beaubien Boulevard, Detroit, MI 48201 USA.

Tel: +1 313745 5515; Fax: +1 313745 5237;

Email: jlusher@med.wayne.edu suffice in convincing the regulatory agencies to grant such indication, certain problems exist. Despite widespread usage of products such as Haemate $\mathrm{P}^{\circledR}$ (produced by Behring in Marburg, Germany and distributed by Centeon, King of Prussia, PA, USA), most published information concerning dosage and efficacy is anecdotal rather than resulting from prospective, controlled studies. Additionally, tests for assaying and labelling products in terms of von Willebrand factor (vWF) content are poorly standardized at present, and tests for assaying postinfusion patient samples for vWF level are fraught with the same problem. While recognizing these concerns, it was decided to survey European and Japanese physicians concerning their usual treatment of persons with von Willebrand disease. 


\section{Materials and Methods}

A two page questionnaire was developed, which asked for information concerning products used, dosage and laboratory monitoring (tests employed, frequency of sampling) for major surgical procedures, and for gastrointestinal bleeding and other mucous membrane bleeding. The questionnaire was aimed at determining clinical guidelines being used to treat von Willebrand disease patients who were not candidates for desmopressin (1-deamino-8-D-arginine vasopressin; DDAVP).

In August 1997 the questionnaire was sent to 25 recognized experts in haemophilia and von Willebrand disease, at 25 large centres in eight European countries (Austria, Denmark, France, Germany, Italy, the Netherlands, Sweden, and UK), and to two experts in two large centres in Japan. Twenty-four of the 27 questionnaires were completed and returned; at least one questionnaire was returned from each of the aforementioned nine countries. Responses were then tabulated and summarized.

\section{Results}

\section{Products judged useful}

FVIII concentrates thought to be useful in treating persons with type 2 and type 3 von Willebrand disease were: Haemate $\mathrm{P}^{\circledR}$, the French $\mathrm{vWF}$ concentrate produced by the Laboratoire Français du Fractionnement (LFB), Alphanate ${ }^{\circledR}$, and the UK's $8 \mathrm{Y}^{\circledR}$ (Table 1). Several respondents noted that a certain product was not available in their country, but they believed it to be effective in von Willebrand disease from reading or hearing the experience of others. Physicians responding from France noted that they used both Facteur von Willebrand LFB (a highly purified vWF concentrate) and Innobrand ${ }^{\circledR}$, LFB (the same product with some FVIII added), the latter being used to correct more quickly FVIII as well as vWF in patients with very low FVIII levels.

When asked if they used cryoprecipitates in such patients, all 25 respondents said no. Several noted that cryoprecipitates were no longer available in their country.

\section{Dosage of product}

When asked 'How do you decide on dosage to be used?', most did not make a distinction between von Willebrand disease types 2 and 3. For major surgery, eight aimed for a certain FVIII level $(>0.50$
Table 1. Responses to query, Which FVIII concentrates do you think are useful in von Willebrand disease patients who are not candidates for DDAVP?'.

\begin{tabular}{lr}
\hline Haemate $\mathrm{P}^{\circledR}$ & 16 \\
French vWF LFB $^{\circledR *}$ & 10 \\
Alphanate ${ }^{\circledR}$ & 2 \\
${\text { UK's } 8 \mathrm{Y}^{\circledR}}$ & 2 \\
\hline
\end{tabular}

Note: Responses were highly dependent on products available in each country, although some respondents noted that a particular product was not available to them but they had heard convincing evidence that it was effective.

*Most noted both French vWF concentrates, a very high purity vWF, and a second which contains more FVIII

$\left.1.00 \mathrm{U} \mathrm{mL}^{-1}\right)$ only, three aimed for a certain ristocetin cofactor (vWF:RCoF) level (0.60-0.80 $\left.\mathrm{U} \mathrm{mL}^{-1}\right)$ only, and 13 aimed for both of these.

For treatment of mucous membrane bleeding, eight of 24 respondents noted that they made a distinction between gastrointestinal bleeding and other types of mucous membrane bleeding (such as epistaxis, oral cavity bleeding and menorrhagia). The eight who made this distinction aimed for higher levels - particularly of vWF:RCoF-in treating gastrointestinal bleeding (these aimed at vWF:RCoF values of $0.80-1.00 \mathrm{U} \mathrm{mL}^{-1}$ ). Among the group as a whole, five responded that they aimed for a certain FVIII level only $\left(0.50-1.00 \mathrm{U} \mathrm{mL}^{-1}\right)$; five aimed for a certain vWF:RCoF level only $\left(0.20-1.00 \mathrm{U} \mathrm{mL}^{-1}\right)$, one with bleeding time (BT) shortening as well; and five aimed for both FVIII and vWF:RCoF values of $0.50-1.00 \mathrm{U} \mathrm{mL}^{-1}$, one with bleeding time correction as well. The other nine respondents stated that they would give an empirical dose $\left(0.20-0.75 \mathrm{U} \mathrm{kg}^{-1}\right.$ FVIII and/or vWF:RCoF) and look for control (cessation) of bleeding; only two of these would aim for correction of the patient's BT.

\section{Monitoring of patients being treated}

When asked, 'How do you monitor the patient who has just undergone major surgery?', none of the 24 respondents made a distinction between von Willebrand disease types 2 and 3. Ten said they would check the patient's FVIII level and vWF:RCoF once daily, three would check the activated partial thromboplastin time (APTT) and FVIII level once daily, three would follow the FVIII, vWF antigen $(\mathrm{Ag})$ and vWF:RCoF once daily, two would follow only the vWF:RCoF once daily, two would follow the FVIII level once daily plus a BT on the first postoperative day only, two would follow the FVIII, vWF:RCoF, vWF Ag, BT and collagen binding assay daily, one would follow all of these except the BT once daily, 
and one would obtain FVIII and vWF:Ag levels daily and BT every $12 \mathrm{~h}$.

To look at this is a slightly different way, 22/24 follow the patient's FVIII level (usually once daily), and of these, 3/24 follow the FVIII level and APTT only. Eighteen of 24 follow the patient's vWF:RCoF level daily, 16 of these with a FVIII level as well. Only two respondents would follow the vWF:RCoF only. Only 5/24 would monitor the patient's BT, and two of the five would do so on the first postoperative day only.

It is noteworthy that several respondents added that, while ordering daily assays of $\mathrm{vWF}$ :RCoF, vWF:Ag and collagen binding, they did not receive results back soon enough to influence a change in dosage. It was generally noted that the FVIII level (as well as APTT and BT, if these were done), was the only test result that came back quickly. Often, the other test results became available 1-2 days later.

When asked, 'How do you monitor the patient who is being treated for significant mucous membrane bleeding?', eight stated that in general they only looked for cessation of bleeding (i.e. without laboratory tests), a ninth would do this for epistaxis but not for gastrointestinal bleeding. Eleven out of 23 monitor both FVIII and vWF:RCoF (usually once daily), 3/24 monitor FVIII daily without vWF:RCoF, while two monitor vWF:RCoF daily without FVIII. Twelve of the 24 respondents would monitor the patient's haemoglobin and haematocrit, 7/24 would monitor bleeding times (usually by a modified Ivy technique), and two would also do collagen binding assays once daily. Several physicians noted that the individual nature of each patient's condition determines which tests they order, if any. As noted for postoperative monitoring, several respondents wrote in that results of tests such as vWF:RCoF, vWF:Ag and collagen binding assays were often not available until 12 days later.

\section{Labelling of concentrates}

A final question was 'What information concerning vial contents (in addition to FVIII content) would be useful to have on the label?' $22 / 24$ stated that they would like to know the vWF:RCoF content; 15 would also like to know the range of $\mathrm{vWF}$ multimers (i.e. are the higher molecular weight multimers present in the concentrate?). Ten of the 24 stated that they would also like to have vWF:Ag content listed, and two would like to have collagen binding listed as well. Two respondents thought that labelling with FVIII content only was sufficient.

\section{Discussion}

While a variety of responses were received, several points are noteworthy. None of the 24 respondents, from nine countries (eight in Europe, and Japan), used cryoprecipitates for treating von Willebrand disease types 2 or 3 . In fact, several physicians noted that cryoprecipitates were no longer available to them, because of a perceived greater risk of bloodborne viral transmission than with virally attenuated plasma-derived FVIII/vWF concentrates.

When asked which products were effective in controlling or preventing bleeding in persons with von Willebrand disease who are not candidates for DDAVP (e.g. von Willebrand disease types 2 and 3; von Willebrand disease type 1 patients with an inadequate response to DDAVP, infants, or those with a history of coronary disease), responses in general reflected products available which the respondent had used. Most respondents listed Haemate $\mathrm{P}^{\circledR}$ and the French product, Facteur von Willebrand $^{\circledR}$.

In terms of initial dosage of product for major surgery, most recipients (13/24) calculated dosage to aim for a certain FVIII level and certain vWF:RCoF level, while 8/24 aimed for a certain FVIII level only. None indicated an attempt to correct the BT. Postoperatively, only $5 / 24$ would check the patient's BT, and two of the five would do so on the first postoperative day only. The most commonly used laboratory test for postoperative monitoring was the FVIII assay (22/24 would obtain a FVIII level once daily), with the vWF:RCoF assay being a close second (18/24 obtain this assay once daily). Seven out of 24 said that they would monitor the vWF:Ag once daily. While combinations of tests were often ordered, the FVIII assay was often the only test result which came back relatively quickly and could thus be used for adjusting dosage.

In treatment of significant mucous membrane bleeding, 8/24 respondents made a distinction between gastrointestinal bleeding and other types of mucous membrane bleeding, generally treating gastrointestinal bleeding more aggressively and with somewhat larger doses of product (aimed at achieving a higher vWF:RCoF level). Overall, for mucous membrane bleeding, almost half of the responding physicians stated that they would give an empirical dose and see if bleeding stopped, without follow-up laboratory monitoring. Laboratory testing was often individualized, depending on the patient's condition, continued bleeding, etc. If laboratory testing was done, 11/24 would monitor both FVIII and 
vWF:RCoF daily, 12/24 would monitor haemoglobin and haematocrit values, and 7/24 would obtain a modified Ivy BT. Two French physicians would also obtain collagen binding assays [11,12] once daily. As noted earlier, results of vWF:RCoF assays and collagen binding assays were generally delayed and thus not of immediate clinical usefulness.

Despite a lack of standardization of $\mathrm{vWF}$ :RCoF assays at present, most respondents (22/24) stated that they would find it useful to have the vWF:RCoF content of plasma-derived FVIII concentrates listed on the label, while 15/24 would also like to know the range of $\mathrm{vWF}$ multimers. If standardized, such information might be quite helpful in product selection and calculation of dosage for particular clinical situations.

\section{References}

1 Kohler M, Hellstern P, Wenzel E. The use of heattreated factor VIII concentrates in von Willebrand disease. Blut 1985; 50: 20-7.

2 Scharrer I. The treatment of von Willebrand's disease. In: Lusher JM \& Kessler CM (eds) Hemophilia and von Willebrand Disease in the 1990s. Elsevier Sci Publ BV, Excerpta Medica, Amsterdam 1991 pp. 463-9.

3 Rodeghiero F, Gill JC, on behalf of the WFH Committee on von Willebrand's disease. Guidelines for the treatment of von Willebrand's disease with plasma derivatives. In: Lusher JM \& Kessler CM. (eds) Hemophilia and von Willebrand Disease in the 1990s. Elsevier Sci Publ BV, Excerpta Medica, Amsterdam 1991 pp. 497-503.

4 Berntorp E, Nilsson IM. Use of a high-purity factor VIII concentrate (Hemate P) in von Willebrand's disease. Vox Sang 1989; 56: 212-7.
5 Rodeghiero F, Castaman G, Meyer D, Mannucci PM. Replacement therapy with virus-inactivated plasma concentrates in von Willebrand disease. Vox Sang 1992; 62: 193-9.

6 Pasi KJ, Williams MD, Enayat MS, Hill FGH. Clinical and laboratory evaluation of the treatment of von Willebrand's disease patient with heat-treated factor VIII concentrate (PBL 8Y). Br J Haematol 1990; 75: 228-33.

7 Goudemand J, Mazurier C, Marey A, Caron C, Coupez B, Mison P, Goudemand M. Clinical and biological evaluation in von Willebrand's disease of a von Willebrand factor concentrate with low factor VIII activity. Br J Haematol 1992; 80: 214-21.

8 Scott JP, Montgomery RR. Therapy of von Willebrand disease. Thromb Hemostas 1993; 19: 37-47.

9 Hanna WT, Bona RD, Zimmerman CE, Carta CA, Hebert GZ, Rickles RF. The use of intermediate and high purity factor VIII products in the treatment of von Willebrand disease. Thromb Haemostas 1994; 71: 173-9.

10 Menache D, Aronson DL. New treatments of von Willebrand disease: plasma-derived von Willebrand factor concentrates. Thromb Haemostas 1997; 78: 566-70.

11 Favaloro EJ, Dean M, Grispo L, Exner T, Koutts J. von Willebrand's disease: use of collagen binding assay provides potential improvement in laboratory monitoring of desmopressin (DDAVP) therapy. Am J Hematol 1994; 45: 205-11.

12 Favaloro EJ, Facey D, Grispo L. Laboratory assessment of von Willebrand factor: use of different assays can influence the diagnosis of von Willebrand's disease, depending on differing sensitivity to sample preparation and differential recognition of high molecular weight vWF forms. Am J Clin Pathol 1995; 104: 264-71. 